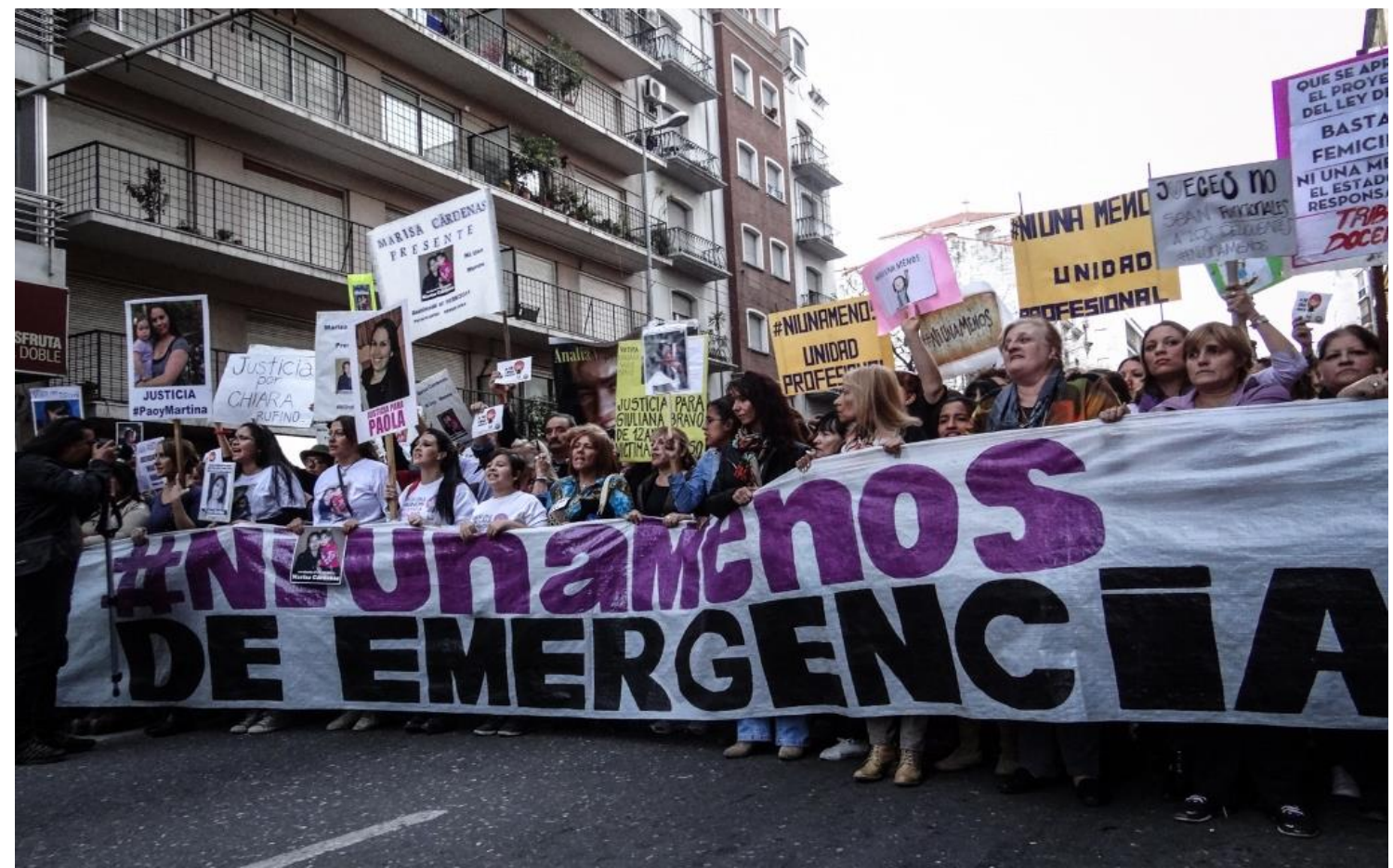

FOTOS: Irina Morán - Revista Alfilo - Periodista Feminista. Militante de Ni Una Menos Córdoba y Mujeres por un parto Respetado 


\title{
A BASE NACIONAL COMUM CURRICULAR E A SUPERAÇÃO DE CONFLITOS EM UM PROJETO EDUCATIVO
}

\begin{abstract}
Rudinei Barichello Augusti ${ }^{1}$
Resumo: Este artigo compreende o estudo, revisão, investigação sobre a Base Nacional Comum Curricular, bem como aborda a superação de conflitos para o desenvolvimento do projeto educativo. $\mathrm{O}$ mesmo apresenta a fundamentação legal da Base Nacional Comum Curricular, bem como a forma esses elementos legais foram se tornando legítimos no decorrer da história. Após a fundamentação dos aspectos legais, históricos, culturais e sociais da Base, apresentam-se duas barreiras e três conflitos que precisam ser superados na dinâmica da Base Nacional Comum Curricular. A primeira barreira imposta ao currículo escolar refere-se ao afastamento do professor, do aluno, do agente educacional e dos pais, do exercício político-pedagógico e educacional das escolas. A segunda é consequência do veio da Pedagogia Tradicional, que emprega a existência de um conhecimento exterior e prévio da escola que deve ser apreendido e aprendido por ela. Já os conflitos são a superação da racionalidade técnica, a superação da epistemologia reguladora e a superação dos conflitos culturais. Nesse sentido, o que se busca é compreender a Base Nacional Comum Curricular a partir de seu contexto imbricado pedagógica e politicamente.
\end{abstract}

Palavras-chave: BNCC. Projeto educativo. Superação de conflitos.

\section{THE COMMON NATIONAL CURRICULAR BASE AND THE EXCEPTION OF CONFLICTS IN AN EDUCATIONAL PROJECT}

\begin{abstract}
This article includes the study, review, investigation, on the National Common Curricular Base, as well as discusses the overcoming of conflicts for the development of the educational project. The same presents the legal basis of the National Curricular Common Base, as well as, in what way these legal elements became legitimate in the course of history. After the foundation of the legal, historical, cultural and social aspects of the Base, there are two barriers and three conflicts that need to be overcome in the dynamics of the National Curricular Common Base. The first barrier imposed on the school curriculum refers to the withdrawal of the teacher, the student, the educational agent and the parents, the political-pedagogical and educational exercise of the schools. The second is a consequence of the tradition of Traditional Pedagogy, in which it employs the existence of an external and prior knowledge of the school that must be apprehended and learned by it. Already the conflicts are the overcoming of the technical rationality, the overcoming of the regulatory epistemology and, the overcoming of the cultural conflicts. In this sense, what is sought is to understand the National Common Curricular Base from its context imbricated pedagogically and politically.
\end{abstract}

Keywords: BNCC. Educational project. Conflict overcoming.

\section{INTRODUÇÃO}

Desde os tempos mais remotos, a existência humana sempre se deu pelo viés do conflito. Dos problemas mais simples que rodeavam a vida cotidiana, aos mais complexos, como, por exemplo, a vida e a morte, o movimento de conflitar-se sempre esteve presente. Existir é encontrar-se em conflito. A palavra conflito, em seu sentido etimológico, segundo Rezende (2014, p. 77), origina-se do latim conflictus e significa "lutar contra, encontro, ataque, investida". Assim, o encontro é o lugar, por excelência,

\footnotetext{
${ }^{1}$ Licenciatura Plena em Filosofia, Mestre em Educação nas Ciências e Doutorando em Educação nas Ciências pela UNIJUÍ - Universidade Regional do Noroeste do Estado do Rio Grande do Sul. Atualmente, é professor de Filosofia e Sociologia, Extensionista de Formação Continuada de Professores. E-mail: rudinei.augusti@gmail.com
} 
do conflito. É no encontro, portanto, no conflito, que os homens mediatizados pelo mundo o transformam. Segundo Freire (1979, p. 42), "O diálogo é o encontro entre os homens, $[\ldots]$ o diálogo impõe-se como o caminho pelo qual os homens encontram seu significado enquanto homens; o diálogo é, pois, uma necessidade existencial".

Nesse sentido, surge a necessidade do movimento dialético-educativo. Em seu sentido etimológico, segundo Marcondes (2001, p. 53), o termo dialética origina-se do latim dialectica e do grego dialektike, que tanto, em uma quanto em outra, significam “discussão". Já a compreensão de diálogo (MARCONDES, 2001, p. 54), do grego dialegesthai e do latim dialogus significam "conversar". Portanto, dialogar e discutir não pressupõe o mesmo entendimento. Por mais que o pensamento liberal tenha reduzido o entendimento de diálogo à mera conciliação de disputas, ainda se assume que o diálogo seja o pressuposto inicial para o encontro que gera a discussão.

$\mathrm{Na}$ História da Filosofia, bem como na Filosofia da Educação, existem vários conceitos de dialética, mas utilizar-se-á, aqui, a compreensão de dialética em Marx, pois o mesmo a compreende como método. Método, do latim méthodus (REZENDE, 2014, p. 229), significa “caminho". A dialética marxista compreende a discussão como caminho, ou seja, uma vez fundamentada no materialismo histórico, ela é composta por estágios de mudança e movimento. No entanto, o movimento dialético pressupõe o diálogo, o encontro e a discussão.

Uma vez que inseridos em um tempo de mudanças constantes, tempo de "[...] mutações vertiginosas produzidas pela globalização, a sociedade de consumo e a sociedade de informação" (SANTOS, 1996, p. 15), lugar de discrepância entre a possibilidade e os interesses técnicos e o desejo de uma sociedade melhor - espaço e espaço de conflito, diálogo, encontro e discussão são indispensáveis. No entanto, ao mesmo tempo que esse espaço e tempo de conflitam, são, por excelência, lugares privilegiados para a discussão, podem, de outra forma, se tornarem incompatíveis com o movimento dialético-educativo, em que educar é uma prática de liberdade.

A auto-suficiência é incompatível com o diálogo. Os homens que não tem humildade ou a perdem, não podem aproximar-se do povo. Não podem ser seus companheiros de pronúncia do mundo. Se alguém não é capaz de sentir-se e saber-se tão homem quanto os outros, é que lhe falta ainda muito para caminhar, para chegar ao lugar de encontro com eles. Neste lugar de encontro, não há ignorantes absolutos, nem sábios absolutos: há homens que em comunhão, buscam saber mais (FREIRE, 1987, p. 46).

A partir do momento em que o homem vai estabelecendo relações com sua 
realidade, estando nela ou com ela, seja se construindo e a reconstruindo, vai transformando o seu mundo. Construir-se e reconstruir-se, nesse sentido, significa estar em constante movimento de diálogo, encontro e discussão. Porém, sabe-se que,

[...] o que cada pessoa seleciona para 'ver' depende muito de sua história pessoal e principalmente de sua bagagem cultural. Assim o tipo de formação de cada pessoa, o grupo social a que pertence, suas aptidões e predileções fazem com que sua atenção se concentre em determinados aspectos da realidade, desviando-se de outros. Do mesmo modo, as observações que cada um de nós faz na nossa vivência diária são muito influenciadas pela nossa história pessoal, o que nos leva a privilegiar certos aspectos da realidade e negligenciar outros. (LUDKE; ANDRÉ, 1986, p. 25)

Diante da constituição social de cada sujeito, apontada acima como singular, salienta-se a necessidade do desenvolvimento de uma permanente atitude crítica, responsável pela integração do sujeito, que supera o ajustamento social, possibilitando o diálogo, o encontro e a discussão sobre as abordagens complexas e significativas de seu tempo. À medida em que os sujeitos vão resolvendo as questões emergentes de seu tempo que são correspondentes a novos anseios, exige do mesmo um novo olhar sobre os velhos temas.

Construir-se e constituir-se como sujeito histórico representa, por vezes, oporse, em outras, comportar-se, afirmando-se como sujeito. Sua maximização ou minimização, humanização e desumanização dependem de sua compreensão, diálogo, encontro e discussão dos aspectos históricos.

[...] é o pensar em relação à realidade, ao conteúdo - a relação entre as formas e estruturas do pensamento do sujeito e aquilo que este não é. Este sentido mais profundo de consciência ou faculdade de pensar não é apenas o desenvolvimento lógico formal, mas ele corresponde literalmente á capacidade de fazer experiências. Eu diria que pensar é o mesmo que fazer experiências intelectuais (ADORNO, 2003, p. 151).

Nesse sentido, estabelecer o diálogo, o encontro e a discussão possibilita a realização de conexões entre os saberes que constituem os agentes da educação, suas práticas e seus tensionamentos teóricos. Em conexão às práticas e aos tensionamentos teóricos, está a luta de todo educador por justiça, direitos, democracia. Essa luta faz com que se ampliem os sentidos e as compreensões do próprio trabalho enquanto educador. A busca pela ampliação do sentido do ser educador implica, necessariamente, estabelecer uma atitude de ruptura com estruturas opressoras e com as relações de opressão nela sustentadas.

[...] os educadores críticos fornecem argumentos teóricos e enormes

Momento: diálogos em educação, E-ISSN 2316-3100, v. 28, n. 3, p. 366-389, set./dez, 2018. 
volumes de evidências empíricas para sugerir que as escolas são, na verdade, agências de reprodução social, econômica e cultural. Na melhor das hipóteses, o ensino escola público oferece mobilidade individual limitada aos membros da classe trabalhadora e outros grupos oprimidos, mas, em última análise, as escolas públicas são instrumentos poderosos para a reprodução de relações capitalistas de produção e de ideologias legitimadoras da vida cotidiana. (GIROUX, 1997, p. 148)

Desarticular as estruturas que sustentam a cultura da dominação, cultura esta que sobrepõe as questões econômicas liberais sobre a construção de valores humanos, é legitimar leituras essenciais na constituição do pensamento crítico, bem como abordagens vivenciais significativas no âmbito da transformação social e, acima de tudo, estabelecer um movimento crítico de busca e construção de um projeto de educação ao qual se possa assentar as crenças, os sonhos e a vontade de educar para a liberdade, justiça e transformação social tão necessárias ao nosso tempo.

Por meio da pedagogia do diálogo, do encontro e da discussão, esta reflexão permite desenvolver uma compreensão consciente, crítica e reflexiva sobre a Base Nacional Comum Curricular, compreendendo-a, como espaço de problematização e construção democrática, ampliando e potencializando o exercício da liberdade que visa aos interessados em educação, abrir caminhos e possibilidades socialmente responsáveis e engajadas na busca pela garantia do direito à educação, à dignidade humana e à construção de sujeitos diversos e multiculturais.

\section{DA HISTÓRIA E FUNDAMENTAÇÃo LEGAL DA BASE NACIONAL COMUM CURRICULAR}

Em 1988, é promulgada a Constituição da República Federativa do Brasil. Conforme definido pelo dicionário Aurélio (1986), a palavra constituição significa o "ato de constituir, de organizar, de estabelecer". Cabe salientar que a noção que predomina sobre constituição está embasada na Lei fundamental - que configura, legitima e limita o poder político, jurídico e social. Dessa forma, as concepções presentes nos direcionamentos da Constituição se referem à dimensão política e seus desdobramentos, à legalidade jurídica e a sua legitimação social. Dessa forma, a Constituição deve apresentar, a partir de suas intencionalidades, além de elementos que estruturam o Estado, a função de concretizar os direitos fundamentais dos cidadãos. 
somente da vontade ou decisão de algum ator político em particular. Sua construção é um processo que abrange a todos os atores políticos relevantes e à cidadania, e não se esgota na edificação de um sistema jurídico ou constitucional. (SALDAÑA, 2001, p. 7)

Entre os direitos sociais presentes na Constituição da República Federativa do Brasil, encontramos o direito à educação. No Artigo 205, afirma-se que "A educação, direito de todos e dever do Estado e da família, será promovida e incentivada com a colaboração da sociedade, visando ao pleno desenvolvimento da pessoa, seu preparo para o exercício da cidadania e sua qualificação para o trabalho.” (BRASIL, 1988, s/p). Destacam-se, nesse sentido, as possibilidades de diálogo, encontro e discussão, a partir do direito, dever, promoção, incentivo, colaboração do Estado, família e sociedade. Também aponta para suas finalidades: desenvolvimento, preparo e qualificação dos agentes em processo.

Dessa forma, a busca pelos direitos e objetivos da aprendizagem e desenvolvimento já aparecem na apresentação da Base Nacional Comum Curricular, como objetivo a ser perseguido pelo coletivo Estado e Sociedade. Para tanto, o documento preliminar foi colocado à disposição para consulta pública via site ${ }^{2}$ críticas e contribuições, no sentido de construir uma Base Nacional Comum Curricular que reúna, em atendimento ao disposto pelo viés legal, bem como pelos anseios de toda sociedade referente à educação, os direitos e objetivos de aprendizagem relacionados às quatro áreas do conhecimento - Ciências da Natureza, Ciências Humanas, Linguagens e Matemática - e seus respectivos componentes curriculares para todas as etapas da educação básica.

O presente documento, fruto de amplo processo de debate e negociação com diferentes atores do campo educacional e com a sociedade brasileira em geral, apresenta os Direitos e objetivos de Aprendizagem e Desenvolvimento que devem orientar a elaboração de currículos para as diferentes etapas de escolarização. (BRASIL, 2016, p. 24)

Quanto à organização da base curricular, no tocante aos conteúdos mínimos para a formação básica, a Constituição Federal, em seu Artigo 210, afirma que "Serão fixados conteúdos mínimos para o ensino fundamental, de maneira a assegurar formação básica comum e respeito aos valores culturais e artísticos, nacionais e regionais" (BRASIL, 1988). A formação básica, a partir dos componentes curriculares e suas respectivas áreas do conhecimento, devem corresponder aos princípios dos direitos

2 Consulta pública disponível no site da Base Nacional Comum Curricular http://basenacionalcomum.mec.gov.br 
da aprendizagem ${ }^{3}$ orientados pelas dimensões ética, estética e política.

Assim, a escola vai além de sua dimensão de compreender o currículo de conteúdos e passa agora, além de contar com a participação de todos para a garantia dos direitos de aprendizagem, também a mobilizar as dimensões ética, estética e política em cada um dos componentes.

Esses diretos fundamentais, que a escola deve contribuir para promover, serão de fato garantidos quando os sujeitos da educação básica estudantes, seus professores e demais partícipes da vida escolar dispuserem de condições para: o desenvolvimento de múltiplas linguagens como recursos próprios; o uso criativo e crítico dos recursos de informação e comunicação; a vivência da cultura como realização prazerosa; a percepção e o encantamento com as ciências como permanente convite à dúvida; a compreensão da democracia, da justiça e da equidade como resultados de contínuo envolvimento e participação. (BRASIL, 2016)

De 1997 ao ano 2000, constroem-se os PCNs - Parâmetros Curriculares Nacionais do Ensino Fundamental e Ensino Médio. A consolidação dos PCNs representa a busca de uma reforma na educação, no sentido de orientar o professor na busca de novos referenciais e metodologias para o trabalho pedagógico. Dessa forma, a Base Nacional Comum Curricular é proposição para consolidar e dar continuidade à reforma educativa proposta pelos PCNs.

Eles não são um documento legal, pois não passaram pela homologação do Conselho Nacional de Educação, por exemplo. E se referem a diretrizes que já foram atualizadas, portanto não podemos dizer que são atuais. A Base Nacional Comum Curricular, em relação ao conteúdo dos Parâmetros Curriculares Nacionais, avança no sentido de sua especificação, em razão dos componentes curriculares, até chegar aos objetivos de aprendizagem e desenvolvimento que são determinados e colocados no documento. (DUTRA, 2016)

Diante do exposto, pode-se compreender que a Base Nacional Comum Curricular não é apenas uma reforma de currículo, mas a solidificação de princípios que orientam a construção do mesmo. Assim sendo, a ideia de currículo passa a envolver a reflexão sobre as práticas, os valores sociais, morais e éticos, bem como a própria vida escolar em sua complexidade. Pensada nessa dinâmica, a superação dos conflitos escolares passa pela dimensão da elaboração e discussão de projetos educativos, cujo currículo não é uma ferramenta de controle, mas, sim, um instrumento reflexivo.

Se a BNCC não é um instrumento de controle curricular, pode-se compreendê-la

\footnotetext{
${ }^{3}$ Os doze Direitos de Aprendizagem estão citados nos Princípios Orientadores da Base Nacional Comum Curricular, em http://basenacionalcomum.mec.gov.br/\#/site/conhecaTextosIntrodutorios
} 
como forma de controle social, uma vez que envolve o estabelecimento de uma base comum acordada nacionalmente. O risco ideológico aumenta ao passo que a homogeneização sobre a educação também aumenta. Sabe-se que as propostas de homogeneização carregam, em seu imaginário neoliberal, somente as evidências de qualidade em termos quantitativos, excluindo, por exemplo, que a qualidade na educação passe pela discussão das políticas de formação de professores, a valorização dos profissionais da educação, a autonomia das escolas na construção curricular, entre outros.

No Brasil, ouço dizer que as políticas destinam-se a melhorar a qualidade do ensino. Mas, o que se quer é melhorar a qualidade do ensino, ou melhorar a qualidade da aprendizagem? Porque não é o mesmo. Posso até melhorar a qualidade do ensino e não tocar na qualidade da aprendizagem. É necessário focalizar a qualidade da aprendizagem, o que implica melhorar a qualidade do ensino. (TORRES, 2000, p. 266).

No entanto, é necessário o movimento dialético no sentido de estabelecer uma comunicação efetiva com a comunidade escolar, sejam pais, professores, funcionários, etc., para que, através do elemento dialógico, constituir propostas para a efetivação de um currículo pedagógico que considere a melhoria da qualidade da educação em sua totalidade para superar os conflitos dos projetos educativos vigentes nas escolas.

Em 2008, a criação do Programa Currículo em Movimento, que compreendia o currículo como fator de qualidade na Educação Básica. Este movimento buscou formular uma possível contribuição curricular nacional para compor a Base Nacional Comum Curricular, subsidiando e orientando os sistemas de avaliação, produção de material didático, formação de professores voltados para a prática docente, buscando efetividade da garantia dos direitos de aprendizagem.

Em 2010, foi realizada a Conferência Nacional da Educação - CONAE/2010. Um dos pontos em pauta foi a regulamentação do regime de colaboração para a efetivação do sistema nacional de ensino. Partindo dessa preocupação, há busca por uma solução cooperativa e colaborativa entre União, Estados, Distrito Federal e Municípios, agindo em conjunto para enfrentar as dificuldades no âmbito escolar. Para fomentar o regime de colaboração e regulamentação, algumas ações foram apresentadas. Entre elas, pode-se citar o estabelecimento de uma de uma "base comum nacional, de maneira a assegurar formação básica comum e respeito aos valores culturais e artísticos, nacionais e regionais" (CONAE, 2010, p.26). 
Entre 2009 e 2011, são lançadas as Diretrizes Nacionais Curriculares para a Educação Infantil, Ensino Fundamental e para o Ensino Médio. De acordo com o documento orientador, a compreensão sobre a base nacional comum, embasada no Art. 26 e 27 da LDB 9.394/96 e em suas relações com a parte diversificada, fica assim descrita:

[...] a base nacional comum interage com a parte diversificada, no âmago do processo de constituição de conhecimentos e valores das crianças, jovens e adultos, evidenciando a importância da participação de todos os segmentos da escola no processo de elaboração da proposta da instituição que deve nos termos da lei, utilizar a parte diversificada para enriquecer e complementar a base nacional comum. [...] tanto a base nacional comum quanto a parte diversificada são fundamentais para que o currículo faça sentido como um todo. (DCNEB, 2013, p.32)

Já, em 2014, através da Lei 13.005/14, regulamenta-se o Plano Nacional da Educação, com vigência de 10 (dez) anos - o PNE 2014-2024. Dentre as Metas do PNE 2014-2024, encontramos quatro que tratam em específico da Base Nacional Comum Curricular. Entre as citadas, encontramos as categorias de universalização da Educação Infantil (Meta 1), Ensino Fundamental (Meta 2) e Ensino Médio (Meta 3). Para atingir essas metas, as estratégias nos diferentes níveis se resumem a estimular e articular os Estados, o Distrito Federal e os Municípios, no sentido de garantir os direitos e objetivos de aprendizagem e desenvolvimento dos alunos diferentes níveis. Soma-se à essas metas, uma quarta proposição, a Meta 7, que busca "fomentar a qualidade da educação básica em todas as etapas e modalidades, com melhoria do fluxo escolar e da aprendizagem de modo a atingir as seguintes médias nacionais para o Ideb" (PNE, 2014, p.33). Para tanto, o PNE 2014-2024 sugere a necessidade da criação de uma base nacional comum dos currículos, mediante pacto entre os entes federados, que atenda os direitos e objetivos de aprendizagem e desenvolvimento dos alunos e, que esta, em sua parte diversificada, respeite a diversidade regional, estadual e local.

Sendo um país em que as desigualdades sociais implicam construção de políticas públicas de Estado, a busca pela equidade e pela qualidade devem passar pela discussão dos entes federados. No entanto, o movimento de colaboração e articulação dos entes também passa pela categoria dialética, quando assume no Artigo 8 da Lei 13.005/14 - que aprova o Plano Nacional de Educação e dá outras providências - que,

$\S 2^{\circ}$ Os processos de elaboração e adequação dos planos de educação dos estados, do Distrito Federal e dos municípios, de que trata o caput deste artigo, serão realizados com ampla participação de representantes 
da comunidade educacional e da sociedade civil. (PNE, 2014, p. 46)

Também, em 2014, aconteceu a 2a Conferência Nacional pela Educação CONAE/2014. A partir da elaboração do documento final, intitulado "O PNE na articulação do Sistema Nacional de Educação - Participação Popular, Cooperação Federativa e Regime de Colaboração", a educação passa a ser compreendia como prática cultural. Esta compreensão privilegia o lócus da escola, mas não o torna exclusivo, impondo a reinvenção dos espaços educativos como espaços de difusão, criação cultural e garantia de direitos. A partir dessas experiências educativo-sociais, o lócus da educação como prática social e cultural implica em investigar o progresso educativo, bem como das experiências de aprendizagem dos alunos.

Uma vez garantida a educação pública como direito pela Constituição Federal de 1988, em seu Artigo 205, cabe compreendê-la nas dimensões laica, democrática, inclusiva e de qualidade social para todos. Além da compreensão de suas dimensões outras questões são relevantes, como por exemplo, a universalização do acesso, a garantia da permanência em todas as etapas do ensino, e ainda, a regulação da educação privada.

Segundo o CONAE (2014, p. 65), sem a superação das mazelas presentes nas dimensões e princípios acima citados, o contexto dos direitos em educação, bem como o respeito à diversidade e o desenvolvimento de uma avaliação que emancipe os sujeitos diante das demandas sociais, ainda são desafios constantes às políticas públicas e às práticas educativas. Essas e outras discussões resultaram em um importante referencial para a mobilização pela Base Nacional Comum Curricular.

Em Junho de 2015, através da Portaria 592/15, o então Ministro da Educação Renato Janine Ribeiro instituiu Comissão de Especialistas para a Elaboração de Proposta da Base Nacional Comum Curricular. Entre as atribuições da Comissão, está a construção preliminar da proposta da Base Nacional Comum Curricular, posteriormente aberta à consulta pública. De acordo com o Artigo 2 da presente Portaria, em seu Parágrafo Único, a discussão pública se dinamiza a partir da consolidação do debate pelos entes federados, bem como pelas instituições e pela sociedade civil.

Parágrafo único. A discussão pública a que se refere o caput desse artigo será realizada nas unidades da federação sob a coordenação das secretarias de educação dos estados, do Distrito Federal e dos municípios, bem como com as associações acadêmicas e científicas que atuam nas áreas de conhecimento da Educação Básica. (BRASIL, 2015, p. 16). 
Assim, em 30 de julho de 2015, é lançado o Portal da Base Nacional Comum Curricular ${ }^{4}$, que apresenta ao público o processo de elaboração da BNC e estabelece canais de comunicação e participação da sociedade neste processo, que segue o seguinte roteiro em ordem cronológica: 30 de julho de 2015 - Lançamento do Portal da BNCC; 16 de setembro de 2015 - apresentação da versão preliminar da BNCC; 15 de Março de 2016 - consulta pública concluída com as diferentes contribuições; abril de 2016 apresentação da $2^{\mathrm{a}}$ versão da BNCC; maio de 2016 - realização dos Seminários Estaduais; e junho de 2016 - apresentação da versão final da BNCC.

Em 1996, é aprovada a LDBEN - Lei de Diretrizes e Bases da Educação Nacional - Lei N. 9.394/96. Em seu Artigo 26, estabelece que a Educação Básica, distribuída em seus diferentes níveis, além de apresentar uma formação curricular comum, também deve atender aos pressupostos da diversidade, entendidos como características regionais, culturais e econômicas.

Os currículos da educação infantil, do ensino fundamental e do ensino médio devem ter base nacional comum, a ser complementada, em cada sistema de ensino e em cada estabelecimento escolar, por uma parte diversificada, exigida pelas características regionais e locais da sociedade, da cultura, da economia e dos educandos. (BRASIL, 1996).

O pressuposto fundante da parte diversificada se desenvolve na autonomia dos projetos pedagógicos que implica reconhecimento dialético entre unidade e multiplicidade, diferença e igualdade. Entretanto, base comum e parte diversificada também se constituem em constante processo de interação dialética em um movimento interno e externo da proposta presente nos projetos educativos escolares. É uma relação de complementaridade e reciprocidade. Base comum e parte diversificada dialogam e convergem para os objetivos propostos, tanto na constituição quanto na Lei de Diretrizes e Bases da Educação Nacional.

A parte diversificada, de contexto específico, e a base comum de conteúdos, solidificados pelas diretrizes do Artigo 27, da LDBEN 9.394/94, consideram as características regionais e locais, seja no âmbito da cultura, da economia, seja no social, organizadas em cada nível de ensino da Educação Básica.

Art. 27. Os conteúdos curriculares da educação básica observarão, ainda, as seguintes diretrizes:

I - a difusão de valores fundamentais ao interesse social, aos direitos e

\footnotetext{
${ }^{4}$ Disponível em: http://basenacionalcomum.mec.gov.br/\#/site/inicio
} 
deveres dos cidadãos, de respeito ao bem comum e à ordem democrática;

II - consideração das condições de escolaridade dos alunos em cada estabelecimento;

III - orientação para o trabalho;

IV - promoção do desporto educacional e apoio às práticas desportivas não-formais. (BRASIL, 1996).

Assim, a LDBEN 9.394/96 não compreende a parte diversificada como núcleo comum de conteúdos. Entende e compreende como uma postura aberta ao contexto das instituições escolares, com autonomia sempre necessária ao contexto e à composição dos componentes curriculares. Dessa forma, qualitativamente, pode-se estabelecer que, diante das múltiplas possibilidades de organização curricular e, diante dos objetivos da educação expressos na Constituição Federal de 1988, bem como na LDBEN 9.394/96, a parte diversificada pode ser materializada coerentemente, atendendo ao princípio da flexibilidade e da dialética entre a unidade e a multiplicidade, diferença e igualdade, substanciados por meio de projetos pedagógicos condizentes com os princípios de formação cidadã, política, ética e estética,

\section{A BASE NACIONAL COMUM CURRICULAR COMO POSSIBILIDADE DA SUPERAÇÃO DAS BARREIRAS E CONFLITOS EM UM PROJETO EDUCACIONAL}

A base para a construção de um novo projeto educativo deve tomar como ponto de partida a superação dos conflitos epistemológicos. A reconstrução dos saberes históricos contextualizados significam, agora, a possibilidade do conflito epistemológico. Doravante à descentralização da postura racionalista do conhecimento moderno, produz-se, em nossos tempos, identidades culturais descentradas. Assim, é necessário

[...] mapear as mudanças conceituais através das quais, de acordo com alguns teóricos, o "sujeito" do Iluminismo, visto como tendo identidade fixa e estável, foi descentrado, resultando nas identidades abertas, contraditórias, inacabadas, fragmentadas, do sujeito pós-moderno. (HALL, 2003, p. 46).

A proposta de um projeto educativo baseado em conhecimentos é, por meio do conflito do conhecimento como prática social do conhecimento, ou seja, "[...] o conhecimento é uma prática social na medida em que é protagonizado e mobilizado por 
um grupo social, atuando num campo social em que atuam outros grupos rivais protagonistas ou titulares de formas rivais de conhecimento." (SANTOS, 1996, p.17). Santos (1996, p. 17) ainda corrobora, “[...] produzir imagens radicais e desestabilizadoras dos conflitos sociais em que se traduziram no passado, imagens capazes de potenciar a indignação e a rebeldia". Dessa forma, submeter a educação ao inconformismo é também recusar a opressão social enquanto elemento normalizado, aceito de forma banal pelas populações.

Acordados com a matriz pedagógica curricular freireana, o currículo, compreende o entendimento de ser humano como inacabado. Em outras palavras, isto quer dizer de uma educação que tem vocação para ser mais, através de um movimento dialético de busca. Na verdade, o inacabamento do ser ou sua inconclusão é próprio da experiência vital. Onde há vida, há inacabamento. (FREIRE, 2002, p.55). Um projeto educativo deve conter em si o movimento dialético-crítico, que estabelece vínculos estreitos entre educação e política, educação e luta de classes. Por intermédio da educação, os sujeitos deixam de ser meros agentes bancários e a escola, fiel depositária, para, frente aos desafios de seu tempo, constituírem o resgate de uma concepção universal de educação. No mesmo sentido, ser ator político diante de um projeto educativo é desenvolver-se em múltiplas potencialidades de transformação social, ancoradas na perspectiva da formação humana-crítica.

Nesse sentido, uma Base Nacional Comum Curricular deve atentar para sua dimensão dialógica. Não pode, sob hipótese alguma, sufocar as inúmeras experiências antropológicas, culturais e sociais. Deve expressar os valores culturais, científicos, pedagógicos e filosóficos, entre outros, em uma dinâmica cujo deslocamento do tradicional para o inovador permita aos sujeitos construtores de sua história, na leitura de mundo, reconhecer a sua própria dimensão social-transformadora, isto é, reconhecerem-se como sujeitos construtores de sua própria história.

Os projetos educativos não são apenas escolares. Assim sendo, o conflito se localiza na dimensão social dos projetos educativos escolares. É no aspecto sociocultural que se encontra a nossa existência e o nosso fazer-existir histórico. Nesse espaço, "existir é [...] um modo de vida que é próprio do ser capaz de transformar, de produzir, de decidir, de criar, de recriar, de comunicar-se" (FREIRE, 1982, p. 66). O conflito nos projetos educativos é resultado do movimento teoria-prática, movimento que comunica, estabelece relações e possibilita a crítica. Esta é a práxis educativa como movimento dialético. É nela que se encontram as diferentes aspirações culturais, 
científicas, pedagógicas, filosóficas, econômicas, ideológicas e políticas. Mas, em contrapartida, somente homens e mulheres são produtores de cultura e é nela que atribuem significado ao que criam, inovam ou transformam. A cultura é um elemento agregador da relação homem x mundo. $\mathrm{O}$ homem faz/produz cultura, serve como esforço recriador em um mundo que não foi criado por ele.

A possibilidade de reflexão e, através dela o movimento de diálogo com os homens e com o mundo, insere, nos projetos educativos, um novo paradigma: a compreensão do currículo como um instrumento que organiza a escola, interagindo entre as práticas, seja dos professores, alunos, família, seja dos gestores e da sociedade, que, através de um processo de autorreflexão, formam e reconstroem processos formativos de conteúdos, saberes e conhecimentos. Na autorreflexão, o ponto de partida é a investigação sobre o conhecimento cotidiano e experiências que os sujeitos em educação compartilham e, através da discussão como movimento dialético, reelaboram seus conhecimentos e seu ser, possibilitando a transformação social.

Esta doble dialéctica de lo teórico y lo práctico, por una parte, y el individuo y la sociedad, por otra, se halla en el núcleo de la investigación-acción como proceso participativo y colaborativo de autorreflexión. [...] La doble dialéctica del pensamiento y la acción y del individuo y la sociedad se resuelve, para la investigación-acción, en la noción de una comunidad autocrítica de investigadores activos comprometidos con el mejoramiento de la educación, que son investigadores para la educación. (CARR Y KEMMIS, 1988, p. 192).

Um currículo como base deve trazer, em seu bojo, um projeto de escola democrática, onde não se ensinam apenas conteúdos, mas onde se orientam os sujeitos a construírem e reconstruírem seus saberes. Essa construção ilustra o ideal de compreender a realidade como um todo, superando o saber fragmentado em disciplinas e ingênuo diante da profundidade da compreensão e interpretação dos fatos sociais, políticos e culturais.

Isto requer pensar um currículo que venha a possibilitar uma prescrição de flexibilidade para os que trabalham nele. Ele deve fortalecer a democracia dos saberes, permitindo a toda comunidade escolar acessar e discutir o conhecimento científico, valorizando os saberes cotidianos.

[...] democratizar é construir participativamente um projeto de educação (...) transformador e libertador, onde a escola seja laboratório de prática, de exercício e de conquista de direitos, de formação de sujeitos históricos autônomos, críticos e criativos, cidadãos plenos, identificados com os valores éticos, voltados à construção de um projeto social 
solidário que tenha na prática da justiça, da liberdade, no respeito humano (...) o centro de suas preocupações. (AZEVEDO, 2001, p. 312).

\section{Barreiras impostas ao Currículo Escolar}

Inicialmente, podemos apresentar duas barreiras em relação à base social dos conteúdos e da construção participativa em relação aos currículos. As barreiras, aqui apresentadas como distintas, unem-se quando discutidas na inserção dos projetos educativo-sociais como proposição comum. A primeira barreira imposta ao currículo escolar refere-se ao afastamento do professor, do aluno, do agente educacional e dos pais, do exercício político-pedagógico e educacional das escolas. A segunda é consequência do veio da Pedagogia Tradicional - que emprega a existência de um conhecimento exterior e prévio da escola que deve ser apreendido e aprendido por ela.

Refletindo a primeira barreira, no contexto de materialização do saber curricular, expressa-se o significativo papel político democrático que constitui uma natureza de participação. Participar exige, em primeiro lugar, que se mude a mentalidade de todos aqueles que fazem parte da comunidade escolar, buscando o exercício político-pedagógico e educacional das escolas.

Compreendendo o desafio da materialização do saber em currículo, legitima-se o movimento praxiológico de pensar e agir política e pedagogicamente. Esse desafio se dá no cotidiano da escola enquanto espaço de reflexão das próprias práticas pedagógicas. Diante da primeira barreira, é importante considerar a participação efetiva do professor, do aluno, do agente educacional e dos pais, no exercício políticopedagógico e educacional das escolas, na intenção de enfrentar o autoritarismo político que marca ideologicamente a sociedade do capital, insistindo em uma pedagogia de cunho patrimonialista e repressivo.

Falta, portanto, compreender e reconhecer as marcas de uma base nacional comum curricular que propunha ser democrática enquanto projeto educativo, em que estão evidenciadas a tensão de seus aspectos ideológicos que norteiam e definem a finalidade das ações e reflexões que se concretizarão na vida da escola. Para isso, é importante reconhecer que o currículo é um espaço permeado de elementos ideológicos, culturais e relações de poder que implicam a vinculação do saber formativo aos interesses de grupos situados em posições de vantagem socioeconômicas e que, através da linguagem (aprender e ensinar) produzem o aspecto ideológico do saber acordado com suas proposições de domínio.

Por fim, o currículo possibilita o encontro entre ideologia e cultura, o que 
favorece o desenvolvimento das relações de poder na sociedade, seja em forma de conflito, seja em forma naturalizada. Se, por um lado, o currículo é elemento de legitimação e da naturalização do desenvolvimento das relações de domínio sociais, de outro, é terreno propício para o uso do poder nas mudanças sociais. Doravante, no Brasil, a partir da historicidade da construção curricular presente até então e, como possibilidade de análise da nova Base Nacional Comum Curricular, objetiva interesses e conflitos. Diante do exposto, não se pode desvincular a reflexão sobre o currículo da constituição histórica e social, pois o mesmo é, uma necessidade social, cultural, política e econômica.

Por ser constituído pela necessidade social e histórica, o currículo é resultado dos conhecimentos que uma sociedade considera necessários para que os alunos aprendam. A decisão sobre a necessidade envolve diferentes concepções de mundo e ideologias políticas de sociedade. Os currículos também não são neutros, não apenas porque respondem a um anseio social, mas porque são elaborados a partir de teorias sobre a produção e distribuição de conhecimento.

Um currículo que busca responder unicamente aos anseios da sociedade, em especial aos grupos dominantes, caracteriza a segunda barreira. Esta é caracterizada pela ideia de que deve ser empregado, nas práticas educativas, um conhecimento exterior e prévio da escola que deve ser apreendido e aprendido por ela. Resultado das ideologias e da visão mercantilista da educação, o currículo escolar, inserido na dinâmica capitalista, é lócus das tendências do mercado liberal. Esse processo de massificação da educação tem produzido impactos na produção e distribuição do conhecimento. O enfrentamento dessa abordagem conflitiva no âmbito do currículo acontece quando se reconhece que o saber não existe separado das práticas, ou seja, ocorre o reconhecimento do movimento dialético como princípio do conflitivo.

Uma educação que parte da conflitualidade dos conhecimentos visará, em última instância, conduzir à conflitualidade entre sensos comuns alternativos, entre saberes práticos que trivializam o sofrimento humano e saberes práticos que se inconformam com ele, entre saberes práticos que aceitam o que existe, só porque existe, independentemente de sua bondade, e saberes práticos que só aceitam o que existe na medida em que merece existir, finalmente entre saberes práticos que olham as decisões pelo que está à jusante delas e as converte em consequências fatais e saberes práticos que olham as decisões pelo que está à montante delas e as converte em indesculpáveis opções humanas. (SANTOS, 1996, p. 18).

Surge desse modelo uma reprodução da racionalidade técnica, aliada ao 
positivismo científico, que configura a sociedade servil aos sistemas de trabalho, e estéril no âmbito do pensamento crítico. Aquém das questões históricas do currículo, sabemos que o modelo de racionalidade técnica insere a dinâmica da formação educativa como pragmática no trabalho produtivo, no âmbito do capitalismo e do neoliberalismo. E é sustentado por modelos de currículo que desconsideram a história: lócus por excelência da construção da racionalidade crítica.

\section{O primeiro conflito: a Superação da Racionalidade Técnica.}

$\mathrm{Na}$ história do pensamento ocidental, encontramos a matriz filosófica do Racionalismo e do Empirismo. Remanescente de Platão com a doutrina das ideias, René Descartes, no Século XVII, constrói um modelo de antropocentrismo moderno baseado no princípio do uso Razão como princípio da Ciência Moderna. Junto a isso, o empirismo baconiano propõe o conhecimento da natureza como forma de domínio. Portanto, o modelo moderno de constituição do antropocentrismo ocidental foi configurado pelo conhecimento científico e sua aplicação técnica.

De fato, a racionalidade técnica, presente nos projetos educativos, norteia a eficácia do conhecimento pela sua aplicabilidade. Imbuídos de racionalidade cognitivoinstrumental, o sucesso da matriz de saber se dá na transformação material da realidade, ou seja, transformar a ciência/conhecimento em força produtiva. Logo, a conversão do conhecimento em bens e serviços pressupõe a configuração dos sistemas modernos educativos, em que a medida do saber é a aplicação técnica da ciência.

Essa proposta de racionalidade técnica implica alguns conflitos:

Quem aplica o conhecimento está fora da situação existência em que incide a aplicação e não é afetado por ela.

[...]

A aplicação assume como única a definição da realidade dada pelo grupo dominante e força-a. Escamoteia os eventuais conflitos e silencia as definições alternativas.

$[\ldots]$

A aplicação é unívoca e seu pensamento é unidimensional. Os saberes locais ou são recusados ou são funcionalizados e, em qualquer caso, tendo sempre em vista a diminuição das resistências ao desenrolar da aplicação.

Os cursos da aplicação são sempre inferiores aos benefícios e uns e outros são avaliados quantitativamente à luz de efeitos imediatos do grupo que move a aplicação. Quanto mais fechado o horizonte contabilístico, tanto mais evidentes os fins e mais disponíveis os meios. (SANTOS, 1996, p.19)

As consequências desse conflito, aqui compreendido como racionalidade técnica, impôs o positivismo como forma de resolução dos problemas constituídos pela 
aplicação técnica do conhecimento. Segundo o positivismo, até mesmo os problemas sociais podem ser resolvidos através da ciência, basta compreendê-los a partir de total neutralidade social e política, o que imobiliza os sujeitos e seus sentimentos de mudança social. O problema estava dado: ao mesmo tempo em que se depositava na ciência um imperial sonho de desenvolvimento científico, que não ocorreu, de outro, a aplicação técnica perdia credibilidade, já que agravava, cada vez mais, os problemas sociais.

No entanto, ainda encontramos nos projetos educativos atuais as pretensões desse modelo de aplicação da técnica. Duas são as justificativas: a primeira, "[...] pela inércia da cultura oficial e das burocracias educativas, pela má fé da institucionalidade capitalista que utiliza o modelo de aplicação técnica para ocultar o caráter político e social da desordem que instaura." (SANTOS, 1996, p. 20).

Dessa forma, a Base Nacional Comum Curricular como projeto educativo necessita colocar em conflito o modelo de epistemologia presente nos currículos, com modelos alternativos. Desse conflito, resultará uma nova base epistêmica para os conteúdos a serem trabalhados no processo de ensino-aprendizagem nas escolas.

Os modelos alternativos sustentam-se como alternativos porque superam a aplicação técnica do saber instrumental. Constituem-se pelas situações concretas, ou seja, a ética e o social - residem no equilíbrio das competências argumentativas capacidade humana de chegar a um entendimento - sobre as questões que exigem decisão. Esses modos não excluem a eficácia da aplicação técnica do saber, mas reorientam a aplicação. Por isso, é importante atentar para o contexto que legitima o uso, de forma destrutível, ou melhor, em uma aplicação edificante de ciência.

Em uma perspectiva da construção de uma Base Nacional Comum Curricular democrática e emancipatória, estabelecer a necessidade de uma comunicação para a competência crítica remete a compreender o conceito edificante de ciência em duas abordagens: o reconhecimento da condição emancipatória a partir da aplicação da ciência às condições histórico-materiais dos sujeitos e, em segundo, o espaço do conflito visto como lugar da amplificação cultural, ético e político dos argumentos utilizados pelos grupos em processo protogônico.

De outra forma, na elaboração da Base Nacional Comum Curricular, a aplicação da condição edificante da ciência pressupõe que

Os cientista e os técnicos apostados nela lutam pelo aumento da comunicação e da argumentação no seio da comunidade científica e 
técnica e lutam, por isso, contra as formas institucionais e os mecanismos de poder que nela produzem violência, silenciamento e estranhamento. (SANTOS, 1996, p. 22).

Já que a construção da Base Nacional Comum Curricular conta com a colaboração dos professores das diferentes áreas, é importante que estes percebam que “[...] a transformação dos saberes locais ocorre com a transformação do saber científico e com esta ocorre a transformação do sujeito epistêmico, do ser cientista e do ser técnico.”(SANTOS, 1996, p. 22). Isto implica reconhecer que uma aplicação somente é contextualizada nos discursos locais, próprios de seu contexto de aplicação.

O movimento de superação da racionalidade técnica, em específico da aplicabilidade da ciência, não é solitário. O processo reflexivo para ser validado ou legitimado pelo coletivo precisa ocorrer, também, no coletivo. Transformar é tarefa de igual maneira dos governos, professores, pais, alunos, sociedade civil, a quem possa interessar.

O projeto educativo conflitual faz do conflito o modelo de aplicação técnica e o modelo de aplicação edificante um dos eixos principais do ensino-aprendizagem. Professores e alunos discutem os dois modelos, as diferenças e as semelhanças entre eles e simulam campos de experimentação social em que seja possível visualizar as consequências da adoção de cada um deles. (SANTOS, 1996, p. 22).

Concluindo, porém, a Base Nacional Comum Curricular irá colaborar com a superação da racionalidade técnica enquanto aplicação da ciência, quando assumir que o conflito pedagógico oriundo dos diferentes modelos de aplicação da ciência não estão pré-determinados apriori. Nesse sentido, a qualidade da Base Nacional Comum Curricular só poderá ser medida pela qualidade com que, coerentemente, concebe a experiência humana como opção responsável.

\section{Segundo Conflito: a superação da epistemologia reguladora}

Anteriormente, apresentada como forma de conhecimento hegemônico, tanto na educação quanto fora dela, a Racionalidade Técnica carrega em si uma epistemologia reguladora. A superação dessa epistemologia requer compreender a epistemologia não mais como uma forma hegemônica de conhecimento, de regulação, mas como proposição emancipatória. O movimento de regulação ocorre quando se põem, de um lado, a ignorância e, no outro extremo, a sapiência. O movimento emancipatório, por ser um movimento dialético, pressupõe que a saída da ignorância se dá através de um 
conhecimento chamado solidariedade.

No paradigma moderno, o movimento de regulação se deu com base na fragilização da emancipação enquanto solidariedade. Reconhecida pela rigidez racional do método cartesiano, e sua conversão em força produtiva do capitalismo industrial, a epistemologia moderna comportava-se como conhecimento de regulação. Essa regulação tinha/tem destinatários reconhecidos socialmente, entre eles, podemos encontrar os trabalhadores, operários, mulheres, minorias sociais étnicas e sexuais, entre outros. Ao passo que se encontram em situação social de opressão, também representam um perigo à ordem socialmente imposta, pois, imbuídos de uma epistemologia de solidariedade, negam a neutralidade epistêmica, social e política.

[...] a regulação é a resultante da articulação (ou da transação) entre uma ou várias regulações de controle e processos "horizontais" de produção de normas na organização. A regulação é entendida no sentido ativo de processo social de produção de "regras de jogo" permitindo resolver problemas de interdependência e de coordenação. (MAROY \& DUPRIEZ, op. cit., p. 76)

Diante disso, uma Base Nacional Comum Curricular que queira superar a epistemologia reguladora precisa compreender o conflito pedagógico que há entre um saber como ordem e, de outro lado, um saber como solidariedade. Cabe a ela garantir que as duas formas sejam identificadas como possibilidade de escolha, experimentadas pela epistemologia e pela aplicação da ciência.

\section{Terceiro Conflito - A Superação dos conflitos Culturais}

O terceiro conflito é o cultural. Superar o conflito cultural significa, em primeiro momento, reconhecer que, mais importante que superar a aplicação da ciência enquanto racionalidade técnica, é superar a epistemologia reguladora e, em seu lugar, a emancipação como conhecimento. Agora, cabe discutir como superar os conflitos culturais a partir de um Projeto Educativo.

A característica central de nosso sistema educativo é o movimento culturalmercantil europeu. Desde a abordagem colonizadora do currículo escolar até a cultura não-escolar, encontramos à margem da proposição científica, epistêmica e cultural as culturas indígenas, negras, minorias étnicas etc. No fundo, caracteriza-se como uma proposição imperialista que, mesmo passando por crise no pós-guerra, com suas consequências, ainda predomina.

Algumas lutas se caracterizam no campo cultural. Todas elas carregam, em sua 
bandeira ideológica, o protagonismo dos grupos e os movimentos sociais que lutam pela afirmação da identidade cultural e que aspiram à resistência contra a homogeneização pretendida pela cultura eurocêntrica. Esta, por sua vez, naturaliza, através das relações de dependência econômica dos países mais pobres aos mais ricos, a afirmação e existência das culturas dominantes sobre as dominadas. Enquanto cultura, a imposição global de características culturais eurocêntricas se opõe à diversidade das características locais dos povos nos países subdesenvolvidos.

A Base Nacional Comum Curricular como proposta de superação dos conflitos culturais deve colocar o conflito cultural em seu centro, problematizando a resistência e a inércia em mudar o ensino das culturas dominantes, trazendo e atualizando saberes necessários para compreensão do currículo como lugar de contexto. A superação dos conflitos culturais não representa um movimento de ruptura ou de criação de guetos incomunicáveis. Pelo contrário, a Base Nacional Comum Curricular deve ser um dispositivo de comunicação para discussão dos conflitos culturais.

Mais do que isso, não apenas o combate de um ensino eurocêntrico que assinala o imperialismo cultural, mas o resgate do multiculturalismo. Para o campo educativo, diante dos projetos educativos, compreender o multiculturalismo como um modelo de interculturalidade é reconhecer as relações entre as diferentes culturas, sem, com isso, afirmar a hierarquização da cultura ocidental. O campo pedagógico é um espaço de experiência de saberes. Portanto, é lugar, por excelência, de comunicação multicultural, assumindo a incompletude da cultura, por isso, a necessidade de diálogo.

Boaventura Souza Santos (1996, p.31) sugere o conceito de hermenêutica diatópica:

A hermenêutica diatópica é um exercício de reciprocidade entre culturas que consiste em transformar as premissas de argumentação de uma dada cultura em argumentos inteligíveis e credíveis noutra cultura.

Dessa forma, um Projeto Educativo que queira ser visto como superação dos conflitos culturais deve perguntar-se sobre a legitimidade do diálogo igualitário entre as diferentes culturais. Devido à dominação cultural, algumas culturas dominadas não se permitem o diálogo intercultural, com receio de que esse venha, apesar das boas intenções, servir de apronfundamento e estratégia da sua dominação.

Por fim, uma Base Nacional Comum Curricular que busque a superação da racionalidade técnica, a superação da epistemologia reguladora e a superação dos conflitos culturais deve, como espaço educativo e orientada a um projeto educativo- 
cultural, acolher o conflito. O conflito, nessa abordagem da superação, tem a intenção de servir para vulnerabilizar modelos dominantes, seja em sua racionalidade técnica e epistemológica, culturalmente impostas.

O acolhimento do conflito pedagógico possibilita a criação de um olhar crítico, desestabilizador, de espanto, indignação, inconformismo e vontade de rebeldia nos estudantes e professores. A partir disso, surgem novas formas de relações entre grupos sociais e pessoas, possibilitando um "relacionamento mais igualitário, mais justo que nos faça aprender o mundo de modo edificante, emancipatório e multicultural. Será este o critério da boa e da má aprendizagem." (SANTOS, 1996, p. 33)

\section{CONCLUSÃO}

Embora se compreenda que seja papel do Estado coordenar os esforços no sentido da construção da Base Nacional Comum Curricular, essa construção merece a racionalidade dialética como lugar colaborativo de toda sociedade civil. Para tanto, a sua abordagem histórico e legal enfoca as diferentes preocupações, que vão desde o âmbito da epistemologia, inclusão, diversidade, até os direitos de aprendizagem e desenvolvimento.

A Base Nacional Comum Curricular precisa ser construída à luz de um projeto de sociedade que considere os embates culturais e políticos. Para tanto, necessita compreender o currículo como um espaço socialmente construído, elaborado e sistematizado, em uma perspectiva crítica, que fomente o humano como elemento central.

Embora as escolas tenham autonomia relativa e compromisso em garantir o direito à educação de qualidade, é de fundamental importância que, através da superação dos conflitos epistemológicos, propunham-se a colaborar através de suas experiências exitosas vivenciadas pelos educadores no cotidiano das escolas. Estas experiências são os fundamentos da transposição do saber curricular para a compreensão social do ensino-aprendizagem.

Por último, é imprescindível que a formulação, discussão e aplicação da Base Nacional Comum Curricular considere o processo democrático que envolva todos os atores educacionais no sentido da melhoria de suas práticas sociais. Para tanto, a superação da racionalidade técnica, a superação da epistemologia reguladora e a superação dos conflitos culturais representam, no âmbito da democracia, os primeiros desafios da base nacional comum curricular. 
Em suma, entende-se que não há teoria educacional que possibilite a construção social do conhecimento sem políticas públicas que agreguem valor ao currículo. $\mathrm{O}$ currículo é constituído socialmente, por isso o mínimo oferecido não poderá se tornar o máximo a ser apreendido. Por fim, fica o desafio da verdadeira função social da base nacional comum curricular, expressa no artigo 205 da Constituição Federal: "A educação, direito de todos e dever do Estado e da família, será promovida e incentivada com a colaboração da sociedade, visando ao pleno desenvolvimento da pessoa, seu preparo para o exercício da cidadania e qualificação para o trabalho".

\section{REFERÊNCIAS}

ADORNO, Theodor W. Experiência e criação artística - paralipômenos à "Teoria Estética". Lisboa: Edições 70, 2003.

AZEVEDO, José C. de. Escola cidadã: construção coletiva e Participação popular. In: SILVA, Luiz, H. da (org.). A Escola Cidadã no contexto da globalização. 4 ed. Rio de Janeiro: Vozes, 2001.

BRASIL, Ministério da Educação. BNCC - Base Nacional Comum Curricular. $2^{\mathrm{a}}$ Versão Revista. Abril/2016. Disponível em:

http://basenacionalcomum.mec.gov.br/documentos/bncc-2versao.revista.pdf Acesso em: 08 jul. 2016.

BRASIL, Ministério da Educação. Lei de Diretrizes e Bases da Educação Nacional LDBEN 9.394/96. Brasília: MEC, 1996.

BRASIL, Ministério da Educação. Princípios Orientadores da Base Nacional Comum Curricular. Disponível em:

http://basenacionalcomum.mec.gov.br/\#/site/conhecaTextosIntrodutorios. Acesso em: 08.07.2016

BRASIL. Portaria N. ${ }^{\circ}$ - 592, De 17 De Junho De 2015. Institui Comissão de Especialistas para a Elaboração de Proposta da Base Nacional Comum Curricular. In: Diário Oficial da União, Brasília, DF, No 114, quinta-feira, 18 de junho de 2015. Seção I, parte 1.

CARR, Wilfred. KEMMIS, Stephen. Teoria Crítica de la Enseñanza - La investigación-acción en la formación del profesorado. Barcelona: Martínez Roca, 1988.

CONAE, Conferência Nacional de Educação. Documento Final. Brasília: MEC, 2010. CONAE, Conferência Nacional de Educação. Documento Final. Brasília: MEC, 2014. DCNEB. Diretrizes Curriculares Nacionais Gerais da Educação Básica. Ministério 
da Educação. Secretaria de Educação Básica. Diretoria de Currículos e Educação Integral. Brasília: MEC, SEB, DICEI, 2013.

DUTRA, Ítalo. Base Nacional Comum Curricular em Debate. Disponível em: http://www.abrelivros.org.br/home/index.php/noticias/6496-base-nacional-comumcurricular-em-debate. Acesso em: 08 jul. 2016.

FERREIRA, Aurélio Buarque de Holanda. Novo dicionário Aurélio da língua portuguesa. 2. ed. revisada e ampliada. Rio de Janeiro: Nova Fronteira, 1986

FREIRE, Paulo. Ação cultural para a liberdade. $6^{\text {a }}$ ed. Rio de Janeiro: Paz e Terra, 1982.

FREIRE, Paulo. Conscientização: teoria e prática da libertação - uma introdução ao pensamento de Paulo Freire. $3^{\text {a }}$ edição. São Paulo: Cortez \& Moraes, 1979

FREIRE, Paulo. Pedagogia da Autonomia. 23 a ed. Rio de Janeiro: Paz e Terra, 2002.

FREIRE, Paulo. Pedagogia do Oprimido. $17^{\mathrm{a}}$ edição. Rio de Janeiro: Paz e Terra, 1987.

GIROUX, Henry. Os professores como intelectuais. Porto Alegre: Artes Médicas, 1997.

HALL, Stuart. A Identidade Cultural na Pós-modernidade. $7^{\mathrm{a}}$ ed. Rio de Janeiro: DP\&A, 2003.

LUDKE, Menga; ANDRÉ, Marli. E. D. A. Pesquisa em educação: abordagens qualitativas. São Paulo: E.P.U., 1986. 99p

MARCONDES, Danilo. JAPIASSÚ, Hilton. Dicionário Básico de Filosofia. $3^{\mathrm{a}}$ ed. revista e ampliada. Rio de Janeiro: Zahar editor, 2001.

MAROY, C.; DUPRIEZ, V. La régulation dans les systèmes scolaires: proposition théorique et analyse du cadre structurel en Belgique. Revue Française de Pédagogie, Paris, n. 130, p. 73-87, jan/mar. 2000.

PNE. Plano Nacional de Educação 2014-2024. Lei 13.005, de 25 de junho de 2014, que aprova o Plano Nacional de Educação e dá outras providências. Série Legislação. N. ${ }^{\circ}$ 125. Brasília: Edições Câmara, 2014.

REZENDE, Antônio M.; BIANCHET, Sandra B. Dicionário do Latim Essencial. 2 ${ }^{\mathrm{a}}$ ed. revista e ampliada. Belo Horizonte: Autêntica, 2014.

SANTOS, Boaventura de S. Para uma Pedagogia do Conflito. In: SILVA, Luiz E. Reestruturação Curricular: novos mapas culturais, novas perspectivas educacionais. Porto Alegre: Sulina, 1996.

ZEPEDA, Jesús. Estado de derecho y democracia. México: Instituto Federal Electoral, 2001. 